\title{
The effect of diabetes on mid-term survival of open heart surgery patients aged over 70 years
}

\author{
๑Illker İnce ${ }^{1}$, @Levent Altınay ${ }^{2}$ \\ ${ }^{1}$ Health Sciences University, Dışkapı Yıldırım Beyazıt Education and Research Hospital, Department of Cardiovascular Surgery, Ankara, Turkey \\ ${ }^{2}$ Zonguldak Bülent Ecevit University, Faculty of Medicine, Department of Cardiovascular Surgery, Zonguldak, Turkey
}

Cite this article as: İnce İ, Altınay L. The effect of diabetes on mid-term survival of open heart surgery patients aged over 70 years. J Health Sci Med 2022; 5(1): 184-188.

\begin{abstract}
Aim: To determine the effect of diabetes on mid-term survival rates of the patients over 70 years of age who underwent an open heart surgery.

Material and Method: Patients who underwent an open heart surgery between November 2016 and May 2019 in our center included in this retrospective study. The patients younger than 70 years were excluded. Patients were divided into two groups: Group 1 included diabetic patients, Group 2 included non-diabetic patients. The patients who were followed-up for less than 24 months were excluded.

Results: A total 389 patients were evaluated and 93 (23.9\%) patients aged over 70 years were included in this retrospective study. Group 1 included 36 (38.7\%) type 2 diabetic patients and Group 2 included 57 (61.3\%) non-diabetic patients. The general mean follow-up time was $48.25 \pm 10.42$ months (range between $30.83-77.07$ months). The number of emergency operations was significantly higher in non-diabetic patients group $(\mathrm{p}=0.005)$. The mortality rates were similar in both groups (30.55\% in Group1, $35.08 \%$ Group 2, $\mathrm{p}=0.652)$. The survival times of the groups were also similar $(63.49 \pm 3.42$ months in diabetic patients, $59.40 \pm 2.67$ months in non-diabetic patients group, $\mathrm{p}=0.254$ ).

Conclusion: Diabetes mellitus has no effect on the mid-term survival rates of the older patients who underwent open heart surgery.

Keywords: Cardiac surgical procedures, diabetes mellitus, survival rates, coronary artery bypass, heart valve diseases
\end{abstract}

\section{INTRODUCTION}

The physiological and anatomical changes occur in both the heart and the vessels as the age of patient increases. These patients may present normal hemodynamic performance at rest, but their cardiac capacity can reach to the limits very quickly in stress situations such as open heart surgery (1). Increased life expectancy, changes associated with end-of-life morbidity, duration of diabetes and other comorbidities in older patients increase the difficulty of the management of health care of these patients $(2,3)$.

Diabetes is one of the major risk factors for major adverse cardiovascular events in the cardiac disease patients $(4,5)$. Also, cardiovascular diseases are reported as the leading cause of mortality in diabetic patients (6). The duration of diabetes is related to the higher incidence of complications and uncontrolled glycemia $(7,8)$.

Herein, we aimed to determine the effect of diabetes on the mid-term survival rates of the patients over 70 years of age who underwent an open heart surgery.

\section{MATERIAL AND METHOD}

The study was carried out with the permission of Zonguldak Bülent Ecevit University Clinical Researchs Ethics Committee (Date: 18.09.2019, Decision No: 2019-146-18/09). All procedures were carried out in accordance with the ethical rules and the principles of the Declaration of Helsinki.

Patients who underwent an open heart surgery between November 2016 and May 2019 in our center were evaluated. The patients younger than 70 years were excluded. The previous diagnosis of type 2 diabetes mellitus and using an anti-diabetic therapy at the time of surgery were the inclusion criteria. The patients who had type 1 diabetes mellitus were excluded. The patients with high blood glucose levels but didn't have previous diagnosis of diabetes and were not using an anti-diabetic regime, were accepted as stress-induced hyperglycemia and were excluded. The patients who were followed-up for less than 24 months were excluded. 
The study patients were divided into two groups. Group 1 included the patients with type 2 diabetes mellitus and Group 2 included non-diabetic patients. The patient data were collected retrospectively from the institutional database. Any oral antidiabetic drugs were ceased $24 \mathrm{~h}$ before surgery and insulin therapy was conducted according to the internal medicine specialist consultation in elective surgery patients. Lactic acidosis was defined as arterial lactate concentration exceeding $5 \mathrm{mmol} / \mathrm{L}$ and $\mathrm{pH} \leq 7.35$ (9). Peak lactic acid levels measured in blood gas analysis in the intensive care unit (ICU) period were taken to compare the lactic acidosis levels between the patient groups.

Statistical analysis: The SPSS (Statistical Package for the Social Sciences) v16 software was used for statistical analysis of the data. Continuous data were expressed as means \pm standard deviation and categorical data were expressed as percentages. The normality of the distribution of the data was tested with KolmogorovSmirnov test. The non-parametric data of the groups were tested with chi-square and Fisher's exact tests. The parametric data of the groups were tested with Student's t-test. P value $<0.05$ was accepted as statistically significant.

\section{RESULTS}

A total 389 patients were evaluated and 93 patients aged over 70 years were included in this retrospective study. Group 1 included 36 (38.7\%) type 2 diabetic patients and Group 2 included 57 (61.3\%) non-diabetic patients. The incidence of peripheral artery disease (PAD) was significantly higher in Group 1 (26 (72.22\%) patients in Group 1 vs 20 (35.08\%) patients in Group 2, $\mathrm{p}<0.001)$. The incidence of cerebrovascular events was significantly higher in Group 1 (13 (36.11\%) patients in Group 1 vs 8 (14.03\%) patients in Group 2, p=0.013). The mean time of duration of diabetes in Group 1 was $23.94 \pm 13.02$ years (ranged from 5 to 49 years). There were no statistically significant differences between the other preoperative variables of the groups. The preoperative data of the groups is presented in Table 1. The most commonly used antidiabetic agent in the study cohort was metformin. The medication types of diabetic patients are presented in Table 2.

The general mean follow-up time was $48.25 \pm 10.42$ months (range between 30.83-77.07 months). The number of emergency operations was significantly higher in non-diabetic patients group $(\mathrm{p}=0.005)$. The mortality rates were similar in both groups $(30.55 \%$ in diabetic patients, $35.08 \%$ in non-diabetic patients group, $\mathrm{p}=0.652$ ). The survival times of the groups were also similar $(63.49 \pm 3.42$ months in diabetic patients, $59.40 \pm 2.67$ months in non-diabetic patients group, $\mathrm{p}=$ 0.254 ) (Figure 1). There were no significant differences in other postoperative data (Table 3 ).

\begin{tabular}{|lcc|}
\hline Table 2. Antidiabetic medication & & \\
\hline & Number & Percent (\%) \\
\hline Metformin & 17 & 47.22 \\
Metformin+Insulin & 5 & 13.99 \\
Insulin & 10 & 27.78 \\
Empagliflozin & 4 & 11.11 \\
\hline
\end{tabular}

\begin{tabular}{|c|c|c|c|}
\hline & Diabetic patients $(n=36)$ & Non-diabetic patients $(n=57)$ & P value \\
\hline Male n (\%) & $25(69.44)$ & $34(59.65)$ & 0.339 \\
\hline Hypertension n (\%) & $20(55.56)$ & $36(63.16)$ & 0.466 \\
\hline Hyperlipidemia n (\%) & $12(33.33)$ & $11(19.30)$ & 0.127 \\
\hline COPD n (\%) & $7(19.44)$ & $12(21.05)$ & 0.851 \\
\hline PAD n (\%) & $26(72.22)$ & $20(35.08)$ & $<0.001$ \\
\hline CVE & $13(36.11)$ & $8(14.03)$ & 0.013 \\
\hline Tobacco abuse n (\%) & $12(33.33)$ & $12(21.05)$ & 0.176 \\
\hline Thyroid dysfunction n (\%) & $7(19.44)$ & $9(15.79)$ & 0.649 \\
\hline Fasting glucose $\mathrm{mg} / \mathrm{dL}$ mean $\pm \mathrm{SD}$ & $192.81 \pm 55.57$ & $112.65 \pm 28.17$ & $<0.001$ \\
\hline $\mathrm{HbAlc}$ mean $\pm \mathrm{SD}$ & $7.88 \pm 1.80$ & $5.51 \pm 0.63$ & $<0.001$ \\
\hline $\mathrm{BMI}$ mean $\pm \mathrm{SD}$ & $27.31 \pm 3.52$ & $27.43 \pm 3.87$ & 0.915 \\
\hline Blood urea mean \pm SD & $63.06 \pm 38.92$ & $51.25 \pm 18.52$ & 0.439 \\
\hline Blood creatinine mean \pm SD & $1.20 \pm 0.64$ & $1.08 \pm 0.52$ & 0.249 \\
\hline Preoperative EF mean \pm SD & $48.47 \pm 10.32$ & $48.81 \pm 9.03$ & 0.955 \\
\hline Preoperative diagnosis n (\%) & & & 0.100 \\
\hline $\mathrm{CAD}$ & $30(83.33)$ & $40(70.17)$ & \\
\hline CAD+Valve disease & $1(2.77)$ & $3(5.26)$ & \\
\hline $\mathrm{CAD}+$ Carotid disease & $2(5.55)$ & $2(3.50)$ & \\
\hline Valve disease & $2(5.55)$ & $1(1.75)$ & \\
\hline Aortic disease & $1(2.77)$ & $11(19.29)$ & \\
\hline
\end{tabular}




\begin{tabular}{|lccc|}
\hline Table 3. Postoperative data & Diabetic patients $(\mathbf{n = 3 6 )}$ & Non-diabetic patients $(\mathbf{n}=\mathbf{5 7})$ & P value \\
\hline Emergency operation & $2(5.55)$ & $17(29.82)$ & 0.005 \\
IABP & $12(33.33)$ & $10(17.54)$ & 0.081 \\
ONBHCAB & $2(5.55)$ & $2(3.50)$ & 0.640 \\
OPCAB & $2(5.55)$ & $5(8.77)$ & 0.559 \\
Exitus & $11(30.55)$ & $20(35.08)$ & 0.652 \\
CPB min mean \pm SD & $107.92 \pm 87.96$ & $94.84 \pm 91.60$ & 0.368 \\
XCL min mean \pm SD & $52.92 \pm 38.84$ & $45.09 \pm 42.28$ & 0.219 \\
Peak lactic acid mmol/L mean $\pm S D$ & $4.15 \pm 0.76$ & $3.96 \pm 1.00$ & 0.299 \\
ICU stay days mean \pm SD & $4.73 \pm 12.78$ & $6.04 \pm 12.59$ & 0.346 \\
In-hospital stay days mean \pm SD & $9.53 \pm 10.77$ & $12.25 \pm 16.73$ & 0.523 \\
Follow-up time months mean \pm SD & $49.01 \pm 11.48$ & $47.76 \pm 9.78$ & 0.449 \\
Survival time months mean \pm SD & $63.49 \pm 3.42$ & $59.40 \pm 2.67$ & 0.254 \\
\hline IABP: Intra-aortic balloon pump; ONBHCAB: On-pump beating heart coronary artery bypass; OPCAB: Off-pump coronary artery bypass; CPB: Cardio-pulmonary bypass; SD: \\
Standard deviation; XCL: Aortic cross-clamp; ICU: Intensive care unit.
\end{tabular}

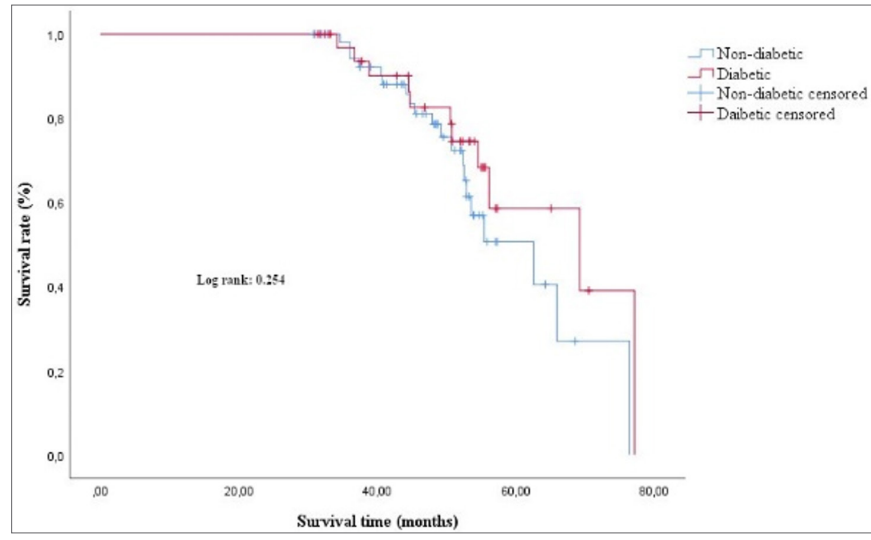

Figure 1. Survival curve related to postoperative survival of diabetic and non-diabetic patients.

\section{DISCUSSION}

The results of this study show that diabetes mellitus have no effect on the mid-term survival and mortality rates of the patients aged over 70 years who underwent open heart surgery.

Age is a generally accepted risk factor for morbidity and mortality after cardiac surgery in the risk scoring systems $(10,11)$. The number and severity of comorbidities such as diabetes mellitus, left ventricular dysfunction, chronic obstructive pulmonary disease, etc. increase in this aged population and these comorbidities also affect the postoperative prognosis of these patients (10).

Wang et al. (12) reported 29\% 5-year mortality rate in patients $>80$ years after cardiac surgery. Also they reported diabetes a significant risk factor for long term survival with a hazard ratio 1.98 regardless of age $(\mathrm{p}=0.011)$ (12). Afilalo et al. (13) reported a decline in the survival curve in one year to two years' period after cardiac surgery in the patients aged $>75$ years. Likosky et al. (14) reported a median survivorship 7.4 years of patients aged 80-84 years and 5.8 years of patients aged over 85 years. They also reported diabetes mellitus a significant risk factor for long term survivorship with a hazard ratio 1.51 (CI 95\% 1.45, 1.57, $\mathrm{p}=0.001$ ).
Schwann et al. (15) followed 11,931 patients who underwent isolated coronary artery bypass grafting (CABG) surgery for an average of $8.7 \pm 4.4$ years including 4377 diabetic patients and reported significantly higher mortality rates in diabetic patients versus non-diabetic patients ( $37.1 \%$ vs $28.6 \%$ respectively, $\mathrm{p}<0.001)$.

In 3-years results of SYNTAX (Synergy Between Percutaneous Coronary Intervention with Taxus and Cardiac Surgery) study, it was reported that significantly lower postoperative major adversecardiac eventsoccurred in CABG patients when compared to the patients who underwent percutaneous coronary revascularization with drug-eluting stents in the presence of diabetes (16). In our study, the mid-term survival and mortality rates were not significantly different in diabetic patients when compared to non-diabetic patients.

The emergency operation and off-pump coronary bypass $(\mathrm{OPCAB})$ surgery rates were significantly higher in nondiabetic patients in our study. We think that this was because of selection bias or incidental.

The duration of diabetes is related to the course of the disease especially in type 2 diabetes. Huang et al. (17) reported that, age and duration of diabetes are independent predictors of the clinical outcome of the disease in older (aged over 60 years) patients. They also reported that, the incidence of the complications such as end-stage renal disease, eye disease, stroke, heart failure, mortality increases as the age of the patient and the duration of the diabetes increase. But their study was not focused on the patients who underwent open heart surgery.

There are different types of antidiabetic drugs such as insulin, alpha-glucosidase inhibitors, biguanides, dipeptidyl peptidase-4 (DPP-4) inhibitors, glucagonlike peptide-1 receptor agonists (GLP-1 receptor agonists), meglitinides, sodium-glucose transporter (SGLT) 2 inhibitors, etc. There are many studies reported 
that SGLT-2 inhibitors (dapagliflozin, canagliflozin, empagliflozin) reduce the adverse cardiovascular events in patients with type 2 diabetes (18-22). In the EMPA-REG OUTCOME (BI 10773 [Empagliflozin] Cardiovascular Outcome Event Trial in Type 2 Diabetes Mellitus Patients) study which was published in 2015, it was reported that empagliflozin (one of the SGLT2 inhibitors) reduced the rates of major adverse cardiovascular events by $14 \%$, cardiovascular death by $38 \%$, all-cause mortality by $32 \%$ in people with type 2 diabetes mellitus and coronary artery disease (18). Verma et al. (22) published subgroup analysis of this study in 2018 including the patients who had a previous history of coronary artery bypass graft (CABG) surgery and reported that adding empagliflozin to the standard antidiabetic medication reduced the risk of cardiovascular death by $48 \%$ and all-cause mortality by $43 \%$. In a recent meta-analysis, it was reported that metformin, a commonly used oral antidiabetic drug in type 2 diabetes, reduced the rates of cardiovascular and all-cause mortalities and cardiovascular events in coronary artery disease (CAD) patients with type 2 diabetes (23). Its undeniable that metformin and empagliflozin have positive effects on preventing the cardiac adverse events in type 2 diabetic patients with CAD. The cohort of our study included the patients who underwent any kind of open heart surgery so we think that is a research subject that if metformin and empagliflozin have any effects on the postoperative cardiac events of these patients too.

Some rare adverse events such as metformin associated lactic acidosis (MALA) can be seen due to metformin therapy (24). The incidence of MALA was reported as 3.3-9.7 cases per 100000 patient-years and the mortality rate was up to $45 \%(25,26)$. On the contrary, Nazer et al. (27) reported that metformin was not associated with lactic acidosis in diabetic patients undergoing CABG operation. In this study, the peak lactic acid levels were slightly higher in diabetic patient group but it was not statistically significant.

Being overweight and obesity are common problems of patients with Type 2 diabetes. These patients need higher doses of insulin therapy to maintain the normal levels of glycemia as the disease progresses.Varol et al. (28) reported that losing weight may reduce the need for insulin and other antidiabetic drugs. We think that body weight control may also reduce postoperative adverse events such as reactive hypoglycemia, impaired wound healing, sternal dehiscence, etc after cardiac surgery.

The limitations of the study are its retrospective design and it is a one-center study. Also we could not perform oral glucose tolerance test in all of the patients because of the lack of patient cooperation. The medical history had to be taken from the patient's relatives but not the patient herself/himself because of the diminished cognitive functions of the patients. We could not assess the effect of antidiabetic medication on the cardiac results of the patients because most of the patients used different types of drugs for various durations through the course of their disease.

\section{CONCLUSION}

Diabetes mellitus has no effect on the mid-term survival rates of the older patients who underwent open heart surgery. Also the mortality rates of these patients seem to be unaffected by the presence of diabetes but more studies should be conducted on this subject.

\section{ETHICAL DECLARATIONS}

Ethics Committee Approval: The study was carried out with the permission of Zonguldak Bülent Ecevit University Clinical Researchs Ethics Committee (Date: 18.09.2019, Decision No: 2019-146-18/09).

Informed Consent: Because the study was designed retrospectively, no written informed consent form was obtained from patients.

Referee Evaluation Process: Externally peer-reviewed.

Conflict of Interest Statement: The author has no conflicts of interest to declare.

Financial Disclosure: The author declared that this study has received no financial support.

Author Contributions: The author declare that they have all participated in the design, execution, and analysis of the paper, and that they have approved the final version.

\section{REFERENCES}

1. Loran D, Zwischenberger J. Thoracic surgery in the elderly. J Am Coll Surg 2004; 199: 773-84.

2. Huang ES, Zhang Q, Gandra N, Chin MH, Meltzer DO. The effect of comorbid illness and functional status on the expected benefits of intensive glucose control in older patients with type 2 diabetes: a decision analysis. Ann Intern Med 2008; 149: 11.

3. Sarıçam O, Kahveci K. Aging and geriatric palliative care. Anatolian Curr Med J 2021; 3: 251-5.

4. Cavallari I, Maddaloni E, Gragnano F, et al. Ischemic and bleeding risk by type 2 diabetes clusters in patients with acute coronary syndrome. Intern Emerg Med 2021; 16: 1583-91.

5. Yeh RW, Secemsky EA, Kereiakes DJ, et al. Development and validation of a prediction rule for benefit and harm of dual antiplatelet therapy beyond 1 year after percutaneous coronary intervention. JAMA 2016; 315: 1735.

6. Lauruschkat AH, Arnrich B, Albert AA, et al. Prevalence and risks of undiagnosed diabetes mellitus in patients undergoing coronary artery bypass grafting. Circulation 2005; 112: 2397-402.

7. Nathan DM, Singer DE, Godine JE, Perlmuter LC. Non-insulindependent diabetes in older patients. Complications and risk factors. Am J Med 1986; 81: 837-42. 
8. Turner RC, Cull CA, Frighi V, Holman RR. Glycemic control with diet, sulfonylurea, metformin, or insulin in patients with type 2 diabetes mellitus: progressive requirement for multiple therapies (UKPDS 49). UK Prospective Diabetes Study (UKPDS) Group. JAMA 1999; 281: 2005-12.

9. Luft D, Deichsel G, Schmulling R-M, Stein W, Eggstein M. Definition of clinically relevant lactic acidosis in patients with internal diseases. Am J Clin Pathol 1983; 80: 484-9.

10. Nicolini F, Agostinelli A, Vezzani A, et al. the evolution of cardiovascular surgery in elderly patient: a review of current options and outcomes. Biomed Res Int 2014; 2014: 1-10.

11.Paparella D, Guida P, Di Eusanio G, et al. Risk stratification for in-hospital mortality after cardiac surgery: external validation of EuroSCORE II in a prospective regional registry. Eur J CardioThoracic Surg 2014; 46: 840-8.

12. Wang W, Bagshaw SM, Norris CM, Zibdawi R, Zibdawi M, MacArthur R. Association between older age and outcome after cardiac surgery: a population-based cohort study. J Cardiothorac Surg 2014; 9: 177.

13. Afilalo J, Steele R, Manning WJ, et al. derivation and validation of prognosis-based age cutoffs to define elderly in cardiac surgery. Circ Cardiovasc Qual Outcomes 2016; 9: 424-31.

14.Likosky DS, Dacey LJ, Baribeau YR, et al. Long-term survival of the very elderly undergoing coronary artery bypass grafting. Ann Thorac Surg 2008; 85: 1233-7.

15. Schwann TA, El Hage Sleiman AKM, et al. Incremental value of increasing number of arterial grafts: the effect of diabetes mellitus. Ann Thorac Surg 2018; 105: 1737-44.

16. Mack MJ, Banning AP, Serruys PW, et al. Bypass versus drugeluting stents at three years in SYNTAX patients with diabetes mellitus or metabolic syndrome. Ann Thorac Surg 2011; 92: 2140-6.

17. Huang ES, Laiteerapong N, Liu JY, John PM, Moffet HH, Karter AJ. rates of complications and mortality in older patients with diabetes mellitus. JAMA Intern Med 2014; 174: 251.

18.Zinman B, Wanner C, Lachin JM, et al. Empagliflozin, cardiovascular outcomes, and mortality in type 2 diabetes. New Engl J Med 2015; 373: 2117-28.

19. Neal B, Perkovic V, Mahaffey KW, et al. Canagliflozin and cardiovascular and renal events in type 2 diabetes. New Engl J Med 2017; 377: 644-57.

20. Wiviott SD, Raz I, Bonaca MP, et al. Dapagliflozin and cardiovascular outcomes in type 2 diabetes. New Engl J Med 2019; 380: 347-57.

21. Verma S, Mazer CD, Al-Omran M, et al. Cardiovascular outcomes and safety of empagliflozin in patients with type 2 diabetes mellitus and peripheral artery disease. Circulation 2018; 137: 405-7.

22. Verma S, Mazer CD, Fitchett D, et al. Empagliflozin reduces cardiovascular events, mortality and renal events in participants with type 2 diabetes after coronary artery bypass graft surgery: subanalysis of the EMPA-REG OUTCOME ${ }^{\oplus}$ randomised trial. Diabetologia 2018; 61: 1712-23.

23. Han Y, Xie H, Liu Y, Gao P, Yang X, Shen Z. Effect of metformin on all-cause and cardiovascular mortality in patients with coronary artery diseases: a systematic review and an updated meta-analysis. Cardiovasc Diabetol 2019; 18: 96.

24. Yayar Ö, Şahin M, Eser B, Savcı Ü. Metformin associated lactic acidosis resulted in cardiopulmonary arrest: a rare case. J Heal Sci Med 2018; 1: 106-9.

25. Lalau JD, Race J-M. Lactic acidosis in metformin-treated patients. Drug Saf 1999; 20: 377-84.

26. Lalau J-D. Lactic Acidosis induced by metformin. Drug Saf 2010; 33: $727-40$
27. Nazer RI, Alburikan KA. Metformin is not associated with lactic acidosis in patients with diabetes undergoing coronary artery bypass graft surgery: a case control study. BMC Pharmacol Toxicol 2017; 18: 38.

28. Varol H, Çitçi A. New treatment approaches in type 2 diabetes: an aspect to case studies. J Med Palliat Care 2020; 1: 12-5. 